\title{
Digitalisation for energy efficiency and flexibility
}

\author{
Nicolas Fatras,', Zheng $\mathrm{Ma}^{3}$ and Bo Nørregaard Jørgensen'
}

'Center for Energy Informatics, Maersk Mc-Kinney Møller Institute, University of Southern Denmark; ${ }^{2}$ Sino-Danish Center for Education and Research, University of Chinese Academy of Sciences; ${ }^{3}$ Center for Health Informatics, Maersk Mc-Kinney Møller Institute, University of Southern Denmark

\begin{abstract}
Introduction and scope
An initial distinction must be made in this chapter between the terms 'digitisation' and 'digitalisation', for which the definitions given in (Bloomberg 2018) will be used from this point on. Digitisation implies a transformation of operations and exchanges of information from an analogue to a digital process. While this requires new digital skills and infrastructure, it does not fundamentally change the business model or operating procedure of the actors involved. On the other hand, digitalisation draws on the infrastructure built up by digitisation to implement a new 'digital economy', with new actors and business models putting forward innovations.
\end{abstract}

'Big Data', machine-learning and the Internet of Things (IOT) are just a few examples of thriving new fields of research and industrial and commercial applications brought about by digitalisation. While digitisation appears to be a prerequisite for digitalisation, successful digitalisation will also lead to further waves of digitisation, in a cyclical process. Physically, the digital world relies on electricity to gather, transfer and process information, making electrification of the energy sector highly compatible with the trend towards digitalisation.

Digitalisation in the energy field can be seen as lying at the crossroads between upstream electrification trends and downstream data-based economies that rely on artificial intelligence (AI). While energy use has always generated data, before digitalisation these data for the most part went unrecorded, or at least were left at too low a resolution to be useful. In return, this lack of data has long favoured analytical over empirical models when it comes to understanding the underlying properties and dynamics of systems. Given the access to large-scale high-resolution data provided by digitisation and subsequently digitalisation, new insights have emerged regarding our physical and societal dynamics. Digitalisation should therefore be understood as the catalyser between the physical and the modelled (or cyber) space, bringing with it new business opportunities and action levers to change the energy sector. The remaining questions are which changes seem the most promising, how these changes will impact on the energy sector in the years to come, and what stakeholders in the field should prepare for.

Although digitalisation will affect most parts of the en- ergy sector, this chapter will focus on energy efficiency and flexibility viewed from the consumption side, while also showing that the boundaries between production and consumption become blurred with digitalisation, which increases the transfer of information in both directions. Energy efficiency focuses on reducing overall energy consumption and is traditionally associated with process optimisation problems, as it is closely linked to economic returns. On the other hand, flexibility concerns the optimal way of dispatching a given quantity of energy, mainly through load time-shifts and fuel-shifts. Compared to energy efficiency, energy flexibility has only received attention much more recently, largely because of the paradigm shift brought about by demand adapting to variable and uncontrollable supply, instead of dispatchable generation traditionally adjusting itself to variable loads. Many digitalisation processes will affect efficiency and flexibility simultaneously, whether in a complementary or conflictual way.

The remainder of this chapter is structured as follows. First, the overall digital maturity of Denmark and China are assessed. Following this, an analysis is performed by end-use sector for both countries. The consumption-side digitalisation potential of each country is then summarized in a Strengths-Weaknesses-Opportunities-Threats (SWOT) table. Finally, current investments in energy digitalisation for both countries are presented, before the chapter ends with a discussion and conclusion on each country's position regarding energy digitalisation and points towards future research directions and possibilities for collaboration.

\section{Digital maturity of Denmark and China}

\section{Denmark}

Denmark has a world-leading position in respect of the digitalisation of public systems and businesses, as well as in its ICT-specialist skills (Lindberg et al. 2019). However, compared to other OECD members, the country is lagging behind with regard to the second wave of digitalisation, particularly in respect of Big Data, the diffusion of Al technology and the appropriate regulations that come with them (Lindberg et al. 2019). Many Danish companies have identified the lack of a qualified workforce in STEM-related subjects relevant to $\mathrm{Al}$ as a major barrier to $\mathrm{Al}$ adoption (Lindberg et al. 2019). Nonetheless, research in new 
technologies is being prioritised by the government, which has recently allocated DKK 50 million to new initiatives in digital technologies at universities (Erhvervsministeriet 2018)

From a physical infrastructure perspective, Denmark has the second highest number of loT devices per capita in the world after South Korea, according to the OECD's Digital Economy Outlook 2015 (OECD 2015)

\section{China}

The digital economy plays a significant role in China: in 2017 , it accounted for $22.1 \%$ of total employment and experienced a growth rate of 20.3\% (Zhu et al. 2020).

In recent years China has imposed itself as a leader in $\mathrm{Al}$, with eleven of the top fifteen Al university programs and more than half of Al start-ups in the world being Chinese (Lindberg et al. 2019). China also has four times the cumulative number of patent applications in the field compared to Europe (Lindberg et al. 2019). China is also emerging as a leader in 5G technology, which it is currently rolling out. By the end of 201956 was available in fifty Chinese cities, making it one of the world's largest $5 C$ deployments (BBC, 2019). The increase in speed, stability and coverage of $5 \mathrm{G}$ is considered particularly important for the development of the energy sector, partly due to the increase in data traffic from loT systems, the push for real-time information (for technical and market operations) and the shift to OPEX 'everything-as-a-service' driven business models (Leligou et al. 2018).

However, China still has several technological, market and policy barriers to overcome in its development of smart grids before it will be able to implement solutions based on digitalisation (see Chapter 5 of this report, on the challenges to smart grid development), as shown by its dependence on imported power electronics to develop its grid (Shell and DRC 2020). Smart grid RED efforts in China in recent years have mainly focused on system-wide issues such as the integration of renewables or grid congestion, while being less oriented towards demand response (Xu et al. 2014).

China is also aiming to push forward its electricity market liberalization with the help of digital solutions. For example, the down-regulation ancillary-services market on the production side in north-east China uses fifteen minute-based settlements, which means automated metering and communication at high resolution (DEA and EPPEI 2018).

\section{Digitalisation for energy end-use sectors}

So far, across end-use sectors, IT has made energy use more convenient, but current efforts are also aiming to make it greener and more intelligent (Shell and DRC 2020). The predicted increase in cross-sector electrification to achieve carbon neutrality and improve system efficiency and flexibility (Van Nuffel et al. 2018) will make the problem at hand significantly more complex, rendering the insights provided by digitalisation very valuable. As digitalisation goes hand in hand with system electrification, it depends on technological innovations in a variety of sectors.

\section{Industry}

In the industrial sector, IT has traditionally been used to improve energy efficiency through energy-management information systems (Shell and DRC 2020). For example, ABB mentions the use of smart sensor solutions which could reduce downtime, increase lifespan and optimize the operation of electric motors, thereby reducing their consumption by up to 10\% (ABB 2017). However, this silo approach does not take the grid's overall needs into account when optimizing each industry's consumption.

In Denmark in 2017, the industrial sector (manufacturing, agriculture and construction) represented 20\% of final energy consumption (DEA 2018). From 1990 to 2013 , final energy consumption declined by $20 \%$ in the sector, while the gross added value increased by 25\% (CNREC and DEA 2015). However, without new initiatives, industrial efficiency is predicted to stagnate from 2020 onwards (DEA 2018). Certain schemes such as the Manufacturing Academy of Denmark (MADE) promote digital innovation and industry 4.0 through initiatives such as MADE Digital (MADE, n.d.). An example of research innovation in this field is the testing of evolutionary algorithms for greenhouse climate control (Sørensen et al., 2016)

In China, industries represent $67 \%$ of the country's overall electricity consumption (Dong et al. 2017), thereby providing huge efficiency and flexibility potential in the power grid. The efficiency of Chinese industry can be greatly improved, as productivity (and therefore partly energy efficiency) remain less than a tenth of productivity in Europe, Japan or the USA (ABB 2017). However, there is believed to be limited potential for further electrification of the industrial sector (Shell and DRC 2020), due to the high-grade heat requirements of processes.

Chinese industrialists' belief in the impact of digitalisation on their sector is nonetheless very high: according to (Beier et al. 2018), 85\% of the study's survey respondents whose companies had a sustainability strategy believed that digitalisation will have a major impact on this strategy, compared to only 53\% for a similar survey in Germany. Yet only $14.7 \%$ are aware of the energy consumption of the machines they operate (Beier et al. 2018)

\section{Residential and services}

'Smart homes' embody the digitalisation of the residential sector: smart heating, cooling, lighting and appliances can optimize and schedule household energy consumption through sensor and actuator feedback, user preferences and learning planning algorithms. For households worldwide in 2040, it is predicted that more than $50 \%$ of electrical appliances will be network-enabled (IEA 2017a). 
For households in Denmark, building energy consumption has declined by $45 \%$ per square metre since 1975, largely without digitalisation, but mainly through better insulation and renovation measures (CNREC and DEA 2015). In general, heating and cooling still have the greatest potential for energy flexibility in buildings in Denmark, particularly through flexibility in district heating (Skytte et al. 2019). As already mentioned in Chapter 8 in this report, digitalisation can play an important role in increasing district-heating efficiency and flexibility by optimising usage dynamics. One example is Leanheat, a subsidiary of Danfoss. Leanheat's software allows heating consumption at the building or district-heating level to be optimized by combining IoT sensors with Al learning processes using weather, usage pattern and ventilation data inputs (Danfoss 2019). However, such initiatives are also confronted with the behavioural aspect of energy consumption. This implies increased efforts in providing consumer information, for which smart meters can be used to obtain data on real-time energy consumption. The mandatory roll-out of smart meters in all households in Denmark by summer 2020 will improve the completeness of consumption data (Kitzing et al. 2016), useful, for example, in forecasting consumption.

While overall final energy consumption in Denmark is only expected to rise by 6\% between 2017 and 2030, the service or tertiary sector is predicted to experience a $44 \%$ increase in consumption, mainly due to the addition of data centres, which are predicted to represent 15\% of total electricity consumption by 2030 (DMCEU 2019). Ironically, this consequence of digitalisation can be improved using digitalisation: in 2016, Google's DeepMind reduced the energy used to cool Google's data centres (one of the primary sources of energy use for data centres) by $40 \%$ using neural networks (Evans and Gao 2016). The potential benefits of Al-optimized cooling relate not only to energy efficiency, but also to energy flexibility, as thermal processes can be shifted more easily in time.

The electricity consumption of buildings in China currently represents only around $15 \%$ of the country's overall electricity consumption (Baležentis and Štreimikiene 2019), but this is bound to change as the economy shifts from high-energy consuming industries to services (Shell and DRC, 2020). Air-conditioning use, which has increased by $13 \%$ per year since 2000 , reached around $16 \%$ of peak electricity load in 2017 (IEA 2019b). While this represents a challenge to the power system, it also provides greater flexibility to the system due to the thermal inertia of cooling loads. To date, very limited data are available on demand-response schemes involving private households (Stern 2015). This can also be explained by the particularly low electricity prices for private consumers in China (IEA 2019a), which create very few incentives to introduce efficiency and flexibility schemes.

\section{Transport}

According to the IEA (IEA 2017a), the impact of digitalisation on the transport sector is the most uncertain.
This is partly because it relies heavily on electrification of the car fleet as a prerequisite. However, the potentials are large: connected vehicles could coordinate charging schedules by sharing information to avoid consumption peaks, vehicle-sharing through digital platforms (apps) could increase transport efficiencies (more passengers per vehicle) and usage rates, and mobility-as-a-Service (MaaS) could simplify energy flexibility operations, as the service-providers play the natural role of aggregator for their car fleets. However, there are concerns whether this increase in convenience will reduce private car ownership or simply attract customers who previously used public transport (Noussan et al. 2020). Another uncertainty in ride-sharing schemes is the potential conflict between efficiency and flexibility with higher usage rates, as higher usage rates improve efficiency but reduce the available charging times, thereby reducing flexibility (Brown et al. 2019). Such behavioural factors should be considered along with adequate regulatory and economic incentives or disincentives.

Denmark is lagging behind other Nordic countries in respect of the electrification of passenger vehicles, partly due to policy shifts in 2016 (IEA et al.). This makes the testing of digitalisation solutions such as optimal battery-charging, vehicle-to-grid or aggregated fleet-ancillary services difficult due to the lack of data and real-life scenarios. However, a few commercial applications such as the CLEVER metering system (CLEVER, n.d.) have emerged with the help of digital-user interfaces. Although CLEVER smart meters are not yet actively engaged in charging optimization for increased flexibility, they do provide a physical infrastructure to which 'smart charging' algorithms could be added in later steps.

As mentioned in the introduction, while electrification increases the potential for digitalisation, it is not a sufficient condition. In 2018, China accounted for $45 \%$ of the world's electric passenger car fleet, and it is one of only five countries with electric car shares above 1\% (IEA 2019c). However, quantitative research on smart-charging potential and economics remains insufficient in China (Jian et al. 2018).

Conversely, digitalisation has played a key role in the impressive uptake of bike-sharing services in China over the last few years through user-friendly mobile apps which reached 130 million users in 2017 (Ibold and Nedopil 2018). 62.9\% of users used bike-sharing services for the 'last mile' (Ibold and Nedopil 2018), typically as a connection between public transport and their workplace, which shows the importance of digitalisation in transport interconnection and coordination.

\section{SWOT analysis of end-use sectors' digitali- sation in Denmark and China}

The competitiveness of Denmark and China with regard to the digitalisation of their energy consumption is summarized in Table 2 using a Strength-Weakness-Opportunity-Threat (SWOT) analysis. This table shows that in several respects Denmark's and China's 


\section{Denmark}

- Smart meter installation for all consumers

- Centralized data collection system DataHub

- High sector-coupling experience with CHP and district heating

- High market liberalization allows financial incentives for flexibility and efficiency

- Unclear/limited role of aggregators

- Lack of Al research centres (Lindberg et al. 2019)

- Lack of STEM-educated workforce (Erhvervsministeriet 2018)

Weaknesses - Industry structured around SMEs is lagging behind in Al adoption (Lindberg et al. 2019)

- Low share of EVs

- -demand response so far limited to industry and other large consumers

- Highly digitalised society in 'first-wave' technologies (Lindberg et al. 2019)

- High acceptance of digitalisation in society (Lind-

Opportunities berg et al. 2019)

- Many collaboration opportunities between researchers and industries through living labs

- Data privacy regulation

- Slow innovation rate in risk-averse energy sector; need for human-verifiable results in potentially

Threats life-threatening activities

- Cyber security restrictions

- Increase in socio-economic inequalities for 'digitally illiterate' populations

\section{China}

- World-leading AI RED

- High share of EV pool with standardized charg-

ing system (Shell and DRC 2020)

- Some of the worldwide largest ICT-based companies by market capitalization: Tencent, Alibaba, China Mobile, Huawei (Johnston 2018)

- Lack of consumption data

- Lack of smart-grid standards

- Dependence on imports for key smart-grid technologies (DC, power electronics, renewable energies) (Shell and DRC 2020)

- Monopoly market structure

- Low incentives for consumer involvement due to very low residential electricity tariffs set by the government (Guo et al. 2017)

- Large potential in centralized energy-intensive industries (Shell and DRC 2020)

- Strong governmental push for DER (Distributed Energy Resources), which need smart grids to be integrated, and energy efficiency, through 13th (and 14th ?) FYP and Made in China 2025 initiative

- Digitalisation and electrification of economy could reduce flexibility from processes with high thermal inertia

- Consumption switch from centralized energy-intensive industries to services and households could make the grid considerably more complex. characteristics complement each other well, demonstrating the potential for fruitful collaboration projects.

\section{Existing projects and main funding direc- tions}

Denmark and China are both making large-scale investments to achieve flexibility and efficiency improvements in their energy sector, but their funding priorities and mechanisms differ based on their specific socio-economic contexts. While Denmark focuses more on consumer-centric solutions with implementation being tested out with private companies, China continues to invest more in supply-side efficiency and flexibility on a national scale, and mainly focuses on industries for demand-side projects, as mentioned in this section. However, both countries seem to rely on small-scale testbeds to test solutions before implementing them on a larger scale.

\section{National-scale funding}

\section{Denmark}

In Denmark, energy technology research projects are mainly funded by Innovationsfonden, EUDP (Energy Technology Development and Demonstration) and ELFORSK. Among the different project categories, those relevant to this chapter are 'Smart grids and systems' and 'Energy efficiency'. In general these two categories represent a significant proportion of the funds allocated to energy-technology research projects, benefiting respectively from DKK 880 and 777 million', which combined represent $42 \%$ of the total funds invested in currently ongoing energy-technology projects (Lindholm et al. 2019). Projects range from individual heat-pump control optimization to municipal school or industrial heat process-scheduling, but remain largely at the demonstration level, as will be shown below.

\section{China}

By contrast, China's funding focus in energy technologies is still much more directed towards the supply side, as the country is still undergoing a net increase in energy consumption. In 2016, the National Energy Administration (NEA) released its Energy Innovation Action Plan (2016-2030), identifying the key sectors for technological innovation in the energy area. Of these

\footnotetext{
1 Financial values are left in the local currency units. However, as this report is being written, values between Danish Krones and Chinese Renminbi (Yuan) are directly comparable, since based on the exchange rates of $18 / 06 / 2020,1 \mathrm{DKK}=0.13$ Euro and $1 \mathrm{RMB}=0.13$ Euro.
} 
fifteen areas, eleven focus on generation-side technologies (or the handling of their consequences, such as nuclear waste treatment), while the remaining four points are divided between energy storage, grid improvement, 'energy internet' technologies and energy efficiency technologies (CNESA 2016).

\section{Research projects and living labs}

\section{Denmark}

In Denmark, in 2018 CenterDenmark was set up as an independent research centre promoting research, development, testing and demonstration of projects focusing on digitally integrated energy systems. One of the largest of these projects is Flexible Energy Denmark (FED), which gathers universities, municipalities, utilities, grid-operators and service-providers together to work on improving consumption flexibility across all sectors through digitalisation. The Centre for IT-Intelligent Energy Systems (CITIES) is another project which focuses on methodologies and ICT solutions to harness the flexibility in the energy system (CenterDenmark, n.d.). In both projects, solutions are tested out in living labs spread throughout the country, providing large and detailed data sets fed into developed models and data analysis tools. The outputs of these projects are forecasting, planning and operations tools and methods for commercial and scientific purposes. Other projects such as the Digital Energy Lab at DTU focus simply on making consumption data available to the research community, thus providing a fertile breeding ground for data-driven solutions to be developed.

In addition, or as part of these research projects, many solutions are tested in Living Labs, where technologies are integrated into everyday life on a small scale, and their effectiveness is monitored. A few involved in demand-side flexibility and efficiency through digitalisation are GreenLabsDK, DOLL Living Lab, GreenLab Skive and, until recently, Energylab Nordhavn (Lindholm et al. 2019).

\section{China}

In China, the testing of smart grid solutions (and energy technologies relying on digitalisation in general) follows a similar approach to its ongoing electricity market liberalization: test beds are limited to a certain number of cities and are still very limited in scope.

Since 2013 four demand-side management (DSM) tests have been carried out in the cities of Suzhou, Beijing, Foshan and Tangshan (Stern 2015). Most of these projects were based on implicit demand response with time-dependent tariffs, real-time prices or peak-load pricing, and focused mainly on industries, along with a few municipal facilities, which were monitored through an online real-time DSM service platform (Stern 2015). One further step was taken in Shanghai, where China's first demand response program was launched in 2014 In this case, over $100 \mathrm{MW}$ of load capacity distributed among industrial and commercial users was centrally controlled through a DR management platform, with financial compensation schemes for load interruptions or displacements (Stern 2015).

In none of these cases are individual consumers or aggregators actively involved in DSM. This can be attributed to the lack of appropriate electricity markets, which 'as they stand, [...] are unable to support full adoption of demand response markets.' (CNESA 2017). The ICT technology deployed in these pilot projects so far mainly has monitoring and informational functions, with very little personalised or data-based strategy optimization. Participation remains compensation-based, and in the case of Beijing, was covered to 93\% by industrial consumers (CNESA 2017). Examples such as the Beijing pilot project which used fifteen-minute interval readings show that high-quality data are available, creating the potential for data analytics and the implementation of accurate market mechanisms (CNESA 2017). However, such innovations also require data access for third-party actors to develop and implement these tools, which is still very limited, given that most smart-meter users do not have access to their own usage data (Guo et al. 2017).

In the case of China, the digitalisation technologies that have been described throughout this report therefore have great potential but can only be used effectively if the appropriate market and policy mechanisms are put in place to support active consumer involvement. The development of data-driven demand-response schemes will therefore closely follow the advances in market unbundling and liberalization. Moreover, as mentioned above, further investments in data-gathering infrastructure (smart controls, sensors, wireless networks) and processes (data-sharing platforms, data access procedures, etc.) must be made a prerequisite for the implementation of demand-side data-driven solutions. Finally, open-access data sources would facilitate the development and implementation of policy, planning, control and forecasting tools for demand response, using China's expertise in Al and other advanced data-analysis methods.

\section{Discussion}

\section{Ambitious goals}

Denmark, as a pioneer in renewable-energy technologies, and China, as the largest market for renewable technologies (IEA 2019a), are both relying on renewables to achieve ambitious carbon-reduction goals, as shown in Chapter 3. However, the nature of VRE (Variable Renewable Energies) power requires a more flexible, interconnected, transparent and efficient energy system to fit demand to the variable supply. This considerable complexification of energy networks can only be achieved through the automation and digitalisation of processes. Both countries are therefore exploring options to integrate innovative digital technologies into the energy sector.

\section{Complementary properties}

Denmark's and China's strengths in the field of digitalisation are quite complementary, which partly explains their strong collaboration in the field of technical-sci- 
ence R\&D described in Chapter 2. Denmark performs well on the data-collection side, with a national rollout of residential smart meters and high loT shares per capita. Data connectivity is also high due to the high rates of 'first-wave' digitalisation, with online services, country-wide Internet access and high smartphone usage rates. The high penetration rate of renewables and the liberalized electricity market provide a good physical, financial and regulatory testbed for innovative data-driven solutions, as is shown by the multitude of 'living labs' spread throughout the country. This decentralized structure also explains the focus of many research projects on consumer-side applications such as transportation and residential loads, which are the two sectors in the country that consume the most energy (IEA, 2017b). Such decentralized projects are supported by Denmark's extensive data-collection and pooling efforts. Energinet's DataHub is an example of data availability being increased through digitalisation. However, several reports have underlined Denmark's weakness in terms of data analytics, with a lack of machine-learning or Big Data tools being taken up by industry. This is partly explained by the lack of a workforce specifically trained in this 'second wave' of digitalisation.

This is where China's strong position in artificial intelligence and its leading universities in the field offer opportunities for collaboration. China's research output in smart grids, the energy internet and machine-learning applied to the energy sector is substantial. But the lack of DERs and the monopoly-based electricity market prevent interconnected consumer-centric solutions based on these machine-learning algorithms from being implemented. Denmark's living labs could provide the appropriate conditions to test these solutions. For its part, Denmark's experience in integrating renewable energy is highly valuable for China, where the reduction in the curtailment rates of installed and future VREs is one of the main drivers for smart-grid developments. On the consumption side, residential and private consumer loads have been investigated less in China, where there is a high focus on industrial consumers. This could partly be due to the high potential in energy efficiency and improvements in flexibility in the manufacturing sector, and partly due to the easier control of larger industrial loads from a centralized grid-management perspective. China will therefore first have to make physical investments in its grid and IOT infrastructure before it can exploit its great potential for flexibility and efficiency improvements with internally developed optimization tools

\section{Challenges and opportunities}

Although both countries will inevitably go through digitalisation of their energy sector, the economic benefits to them both will depend on the capacity of existing players in the energy industry to innovate. (Brown et al., 2019) stress that the energy-utility industry has traditionally been more conservative than other industries. Yet digitalisation is marked by the try fast/fail fast/learn fast approach embodied by GAFAM (Google, Amazon,
Facebook, Apple, Microsoft). These companies have already started to get involved in the energy sector through power purchase agreements with VRE generators and could move down the chain to the retail sector, particularly if digitalisation is extensive. This would force utility companies to retreat from the retail sector and focus on their generation and storage assets (Brown et al. 2019), thus decoupling the retail sector completely from physical production.

This risk is higher for Denmark than for China, as several Chinese companies occupy world-leading roles in the digital economy, from smartphone production, 56 installation and mobile network services to large conglomerate forms of influence such as Tencent and Alibaba, which are involved in almost every aspect of the Chinese economy's digitalisation. While China still needs to catch up in some sectors in order to digitalise its energy system, the importance of its digital economy and the government's support to this sector provide it with great momentum for change. The country's main challenge remains the liberalization of its energy market to provide the necessary conditions for this change to happen.

Denmark must take advantage of its rich energy-consumption databases to push its digitalisation of energy further. The integration of consumption aggregators into energy ecosystems has been identified as a crucial step in the development of demand response (Energinet 2017). However, aggregators face major uncertainties and barriers to market entry, which could partly be solved by improving consumption forecasts, developing insights into market behaviour, increasing flexibility availability times and increasing aggregation pools. Such solutions can typically be implemented with the help of machine-learning tools. Data platforms such as EnergyDataDK, obtained from the EnergyLab Nordhavn project, provide an opportunity to develop, train and test machine-learning methods on real-life applications and assess the impact on the energy system.

\section{Conclusion}

The changes brought about by digitalisation in the energy sector are moving from 'back-office' digitalisation, where the same services as before are being offered, but with greater efficiency and convenience, to 'transformative' digitalisation, which enables new operational and business models (Brown et al. 2019).

The digitalisation of the energy sector becomes increasingly advantageous the more complex the system becomes, driven by the increase in decentralized and variable renewable energies. New digital solutions depend on the availability of data, which requires the installation of connected sensors and actuators, combined with a digital connectivity infrastructure as a backbone, such as 5G, cloud computing and common access databases. With this infrastructure in place, energy flexibility and efficiency can be improved using data analytics, with, for example, machine-learning algorithms. 
Of course, the application to real-life projects will not follow a linear path from data collection to analysis, as data infrastructure will be added to support flexibility and efficiency solutions in an iterative way. This is where testbeds such as those in Denmark and China provide valuable learning experience. However, while most of these live tests report positive results, their influence on the overall energy system is negligible. Future steps will have to analyse the impact of these digital solutions on the energy system once their application becomes widespread.

The complementary properties of Denmark and China are interesting with regard to progress made in different end-use sectors. Denmark's widely decentralized energy sources and liberalized energy market allow digitally enabled prosumer and aggregator participa- tion in decentralised markets to be tested, particularly in the residential sector. Although Denmark's digital infrastructure is also adapted to the integration of electric vehicles, the slow uptake of the EV industry is preventing large-scale implementation. China, on the other hand, has succeeded in developing a strong EV industry, but lags behind in industry efficiency, in which Denmark has many years' experience.

Finally, apart from ensuring the complementarity of their end-use sectors, Denmark and China also complement each other well in terms of expertise in digitalisation. While Denmark is at the forefront of collecting energy consumption data and making it available on platforms such as DataHub, China's acquired expertise in artificial intelligence can provide interesting insights into the data thus obtained.

\section{References}

\section{ABB. 2017. Digitalization: fast track to "Made in China} 2025". Beijing, China.

Baležentis, T. and Štreimikiene, D. 2019. 'Sustainability in the electricity sector through advanced technologies: Energy mix transition and smart grid technology in China'. Energies, 12

BBC. 2019. 'China rolls out 'one of world's largest' $5 \mathrm{G}$ networks.'

Beier, G., Niehoff, S. and Xue, B. 2018. 'More sustainability in industry through Industrial Internet of Things?' Applied Sciences (Switzerland), 8.

Bloomberg, J. 2018. 'Digitization, Digitalization, And Digital Transformation: Confuse Them At Your Peril'. Forbes.

Brown, M., Woodhouse, S. and Sioshansi, F. P. 2019. Consumer, Prosumer, Prosumager: How Service Innovations Will Disrupt the Utility Business Model. Academic Press.

CenterDenmark. n.d. Knowledge bank - Projects [Online]. Available: https://www.centerdenmark.com/en/knowledge-bank/projects/ [Accessed 18-06-2020].

CLEVER. n.d. Tilbagebetaling fra Clever (Refund from Clever) - Webpage in Danish [Online]. Available: https://clever. dk/opladning-hjemme-og-paa-farten/tilbagebetaling/ [Accessed 24-06-2020].

CNESA 2016. 'China's Energy Innovation Action Plan'. China Energy Storage Alliance.
CNESA 2017. 'Beijing's Demand Response Pilot: A Review'. Chinese Energy Storage Alliance

CNREC and DEA 2015. 'The Danish Energy Transformation Roadmap'. CHINA INTERNATIONAL FORUM ON ENERGY TRANSFORMATION. Chinese National Renewable Energy Centre; Danish Energy Agency.

Danfoss. 2019. Leanheat makes buildings smart [Online]. Available: https://www.danfoss.com/en/service-and-support/case-studies/cf/leanheat-makes-buildings-smart/ [Accessed 01/09/2020].

DEA. 2018. 'Denmark's Energy and Climate Outlook 2018 Baseline Scenario Projection Towards 2030 With Existing Measures (Frozen Policy)'. Danish Energy Agency.

DEA and EPPEI. 2018. 3 Region Report on flexibility measures for system integration of variable renewable energy - U.S., Europe, China. Danish Energy Agenct and China Electric Power Planning \& Engineering Institute.

DMCEU. 2019. Denmark's Integrated National Energy and Climate Plan. Danish Ministry of Climate Energy and Utilities.

Dong, K.-Y., Sun, R.-J., Li, H. and Jiang, H.-D. 2017. 'A review of China's energy consumption structure and outlook based on a long-range energy alternatives modeling tool'. Petroleum Science, 14, 214-227.

Energinet. 2017. Market models for aggregators - activation of flexibility. 
Erhvervsministeriet. 2018. Strategy for Denmark's Digital Growth. The Danish Government - Ministry of Industry Business and Financial Affairs.

Evans, R. and Gao, J. 2016. 'DeepMind Al reduces Google data centre cooling bill by 40\%'. Available from: https:// deepmind.com/blog/article/deepmind-ai-reduces-google-data-centre-cooling-bill-40.

Guo, P., Li, V. O. and Lam, J. C. 2017. 'Smart demand response in China: Challenges and drivers'. Energy Policy, 107: pp. 1-10.

Ibold, S. and Nedopil, C. 2018. The Evolution of Free-Floating Bike-Sharing in China [Online]. Available: https:// www.sustainabletransport.org/archives/6278 [Accessed 16-06-2020].

IEA. 2017a. Digitalisation and Energy - Technical report. International Energy Agency.

IEA. 2017b. Energy policies for IEA countries - Denmark 2017 Review. International Energy Agency.

IEA. 2019a. China power system transformation: assessing the benefit of optimised operations and advanced flexibility options. International Energy Agency.

IEA. 2019b. The Future of Cooling in China: Delivering on action plans for sustainable air conditioning. International Energy Agency.

IEA. 2019c. Global EV outlook 2019 - Scaling-up the transition to electric mobility. International Energy Agency.

IEA. 2018. Nordic EV Outlook 2018 - Insights from leaders in electric mobility. International Energy Agency.

Jian, L., Yongqiang, Z. and Hyoungmi, K. 2018. 'The potential and economics of EV smart charging: A case study in Shanghai'. Energy Policy, 119: pp. 206-214.

Johnston, S. 2018. 'Largest companies 2008 vs. 2018, a lot has changed'. MILFORD [Online]. Available from: https:// milfordasset.com/insights/largest-companies-2008-vs2018-lot-changed 2020].

Kitzing, L., Katz, J., Schröder, S. T., Morthorst, P. E. and Andersen, F. M. 2016. 'The residential electricity sector in Denmark: A description of current conditions'. DTU Management Engineering.

Leligou, H. C., Zahariadis, T., Sarakis, L., Tsampasis, E., Voulkidis, A. and Velivassaki, T. E. 2018. 'Smart Grid: a demanding use case for $5 G$ technologies'. 2018 IEEE International Conference on Pervasive Computing and Communications Workshops (PerCom Workshops), 2018. IEEE, 215-220.
Lindberg, B., Andersen, J. R., Hansen, M. A. E., Frandsen, S., Alstrup, S., Krause, S. and Duvold, T. 2019. 'An Al nation? Harnessing the opportunity of artificial intelligence in Denmark'. The Innovation Fund Denmark and Mckinsey Company.

Lindholm, D., Petersen, M., Langvad, N. and Tornbjerg, J. 2019. 'Energi 2019: Energiforskning skaber stærke Rlimaløsninger' (Energy 2019: Energy research creates strong climate solutions) - Document in Danish. Innovationsfonden; EUDP;ELFORSK.

MADE. n.d. MADE Digital [Online]. Available: https://en. made.dk/digital/ [Accessed 24-06-2020].

Noussan, M., Hafner, M. and Tagliapietra, S. 2020. 'The Future of Transport Between Digitalization and Decarbonization: Trends, Strategies and Effects on Energy Consumption'. Springer Nature.

OECD 2015. OECD digital economy Outlook 2015, Organisation for Economic Co-operation and Development.

Shell and DRC 2020. 'China's Energy Revolution in the Context of the Global Energy Transition'. Shell International B.V. and the Development Research Center (DRC) for the State Council of the People's Republic of China.

Skytte, K., Bergaentzlé, C., Fausto, F. and Gunkel, P. A. 2019. 'Flexible Nordic Energy Systems - Summary Report'. Flex4Res Flexible Nordic Energy Systems. Nordic Energy Research.

Sørensen, J. C., Kjær, K. H., Ottosen, C.-O. and Jørgensen, B. N. 2016. 'DynaGrow-Multi-Objective Optimization for Energy Cost-efficient Control of Supplemental Light in Greenhouses'. IJCCI (ECTA), 2016. 41-48.

Stern, F. 2015. Demand response in China - The Market \& Strategic Positioning of Active Players. Azure International.

Van Nuffel, L., Dedecca, J. G., Smit, T. and Rademaekers, K. 2018. Sector Coupling: How Can it be Enhanced in the EU to Foster Grid Stability and Decarbonise?, European Parliament.

Xu, Z., Xue, Y. and Wong, K. P. 2014. 'Recent advancements on smart grids in China'. Electric Power Components and Systems, 42: pp. 251-261.

Zhu, S., Song, M., Lim, M. K., Wang, J. and Zhao, J. 2020. 'The development of energy blockchain and its implications for China's energy sector'. Resources Policy, 66: p. 101595. 